\title{
Probing time-dependent afterslip and viscoelastic relaxation following the 2015 Mw7.8 Gorkha earthquake based on the 3-D finite-element model
}

\author{
Lina Su ${ }^{1,2^{*}} \mathbb{D}$, Fuqiang Shi ${ }^{2}$, Weijun Gan ${ }^{1}$, Xiaoning $\mathrm{Su}^{3}$ and Junyi Yan ${ }^{2}$
}

\begin{abstract}
We analyzed daily displacement time series from 34 continuous GPS stations in Nepal and 5 continuous GPS stations in South Tibet, China, and extracted the first 4.8 years of postseismic motion after the 2015 Mw7.8 Gorkha earthquake. With the longer duration GPS observations, we find that postseismic displacements mainly exhibit southward and uplift motion. To study the postseismic afterslip and viscoelastic relaxation, we built a 3-D spherical finite-element model (FEM) with heterogeneous material properties and surface topography across the Himalayan range, accounting for the strong variations in material properties and surface elevation along the central Himalayan arc. On the basis of the FEM, we reveal that the predicted viscoelastic relaxation of $\mathrm{cm}$ level moves southward to the north of the Gorkha earthquake rupture, but in an opposite direction to the observed postseismic deformation in the south; the postseismic deformation excluding viscoelastic relaxation is well explained by afterslip downdip of the coseismic rupture. The afterslip is dominant during 4.8 years after the 2015 Mw7.8 Gorkha earthquake; the contribution by the viscoelastic relaxation gradually increases slightly. The lack of slip on a shallow portion and western segment of the MHT during and after the 2015 Gorkha earthquake implies continued seismic hazard in the future.
\end{abstract}

Keywords: GPS, 2015 Gorkha earthquake, Postseismic deformation, Afterslip, Viscoelastic relaxation, Finite-element model

\section{Introduction}

On 25 April 2015, the Mw7.8 Gorkha earthquake struck, just $77 \mathrm{~km}$ northwest of Kathmandu, Nepal, resulting in large economic losses and a death toll of up to 8000 (Earthquake Relief Portal 2015). The Himalayan region, accommodating a high convergence rate of $40-50 \mathrm{~mm} /$ year between the overriding Eurasian Plate and the underthrusting Indian Plate (Bilham et al. 1997; Lavé and Avouac 2000), is prone to earthquakes, such as the 1255 and 1934 Mw8 + Nepal-Bihar earthquakes, 1956 Mw8.6 Assam-Tibet earthquake, 2005 Mw7.6 Kashmir

\footnotetext{
*Correspondence: sulinawhu@163.com

${ }^{1}$ State Key Laboratory of Earthquake Dynamics, Institute of Geology,

China Earthquake Administration, Beijing 100029, China

Full list of author information is available at the end of the article
}

earthquake, etc. (Sapkota et al.2013; Bilham 2004; Wang and Fialko 2014). The Gorkha earthquake occurred near the E-W trending Main Frontal Thrust (MFT) (USGS 2015), the most active branch of the Main Himalayan Thrust (MHT), which absorbs about half of MHT convergence (Lavé and Avouac 2000; Kumar et al. 2001). Studies show that the 2015 Gorkha rupture was concentrated in the deeper part of the seismogenic zone, between depths of 10 and $15 \mathrm{~km}$, leaving the unbroken shallow part at high seismic risk (Lindsey et al. 2015; Wang and Fialko 2015; Mencin et al. 2016; Sreejith et al. 2015; Galetzka et al. 2015).

When an earthquake occurs, sudden coseismic stress changes in the surrounding rocks may lead to viscoelastic relaxation in the lower crust and upper mantle, and 
aseismic slip updip and/or downdip of the coseismic rupture (Pollitz et al. 2003; Freed et al. 2004, 2007, 2010; Rousset et al. 2012; Perfettini et al. 2004; Barbot 2010; Savage and Svarc 1992). The postseismic deformation due to the Gorkha earthquake provides valuable constraints to investigate the lithosphere strength and constitutive properties beneath the Himalayan region and Tibetan Plateau. Therefore, the exploration of postseismic transients and what mechanisms govern the postseismic process is of a broad interest. A few of studies focused on the afterslip modeling to explain the rapid transient postseismic deformation (Gualandi et al. 2016; Sreejith et al. 2015; Jiang et al. 2019). With the longer span of data available, some studies investigated various mechanical processes contributed by afterslip and viscoelastic relaxation with and without poroelastic rebound (Mencin et al. 2016; Zhao et al. 2017; Wang and Fialko 2018; Jiang et al. 2018; Jouanne et al.2019; Tian et al. 2020; Liu et al. 2020). The previous studies mostly employed the homogeneous elastic half-space or layered elastic model to explore afterslip (Sreejith et al. 2016; Zhao et al. 2017; Wang and Fialko 2018; Jiang et al. 2018; Jiang et al. 2019), and the layered model or lateral heterogeneous model, which incorporates a low viscous layer beneath the Tibetan Plateau to investigate viscoelastic relaxation (Zhao et al. 2017; Wang and Fialko 2018; Jouanne et al. 2019; Tian et al. 2020).
Material heterogeneity affects surface deformation due to fault slip (Masterlark et al. 2001 2003; Hughes et al. 2010; Kyriakopoulos et al. 2013; Wiseman et al. 2015; Tung and Masterlark 2016; Hu et al. 2016; Klein et al. 2016; Hsu et al. 2014; Hines et al. 2016; Pratama et al. 2017; Suito 2017; Freed et al. 2017). Therefore, the homogenous or layered earth model assumption for the Himalayan range, which has strong variations in material properties (Cattin et al. 2001; Monsalve et al. 2006; Schul.te-Pelkum et al. 2005), inevitably introduces bias into the modeling (Kyriakopoulos et al. 2013; Tung and Masterlark 2016; Suito 2017;). In this paper, we build a 3-D spherical finite-element model (FEM) considering heterogeneous material properties and surface topography across the Himalayan range to investigate the aseismic afterslip and the viscoelastic relaxation following the 2015 Gorkha earthquake, using extracted postseismic displacement from continuous GPS (cGPS) data in Nepal and southern Tibetan Plateau over 4.8 years after the event.

\section{GPS data and postseismic deformation GPS processing}

We collected raw RINEX data from 39 cGPS sites within an area between $78-92^{\circ} \mathrm{E}$ and $23-34^{\circ} \mathrm{N}$ (Fig. 1). GPS sites in Nepal include 25 sites operated prior to the Gorkha earthquake and 9 sites deployed immediately

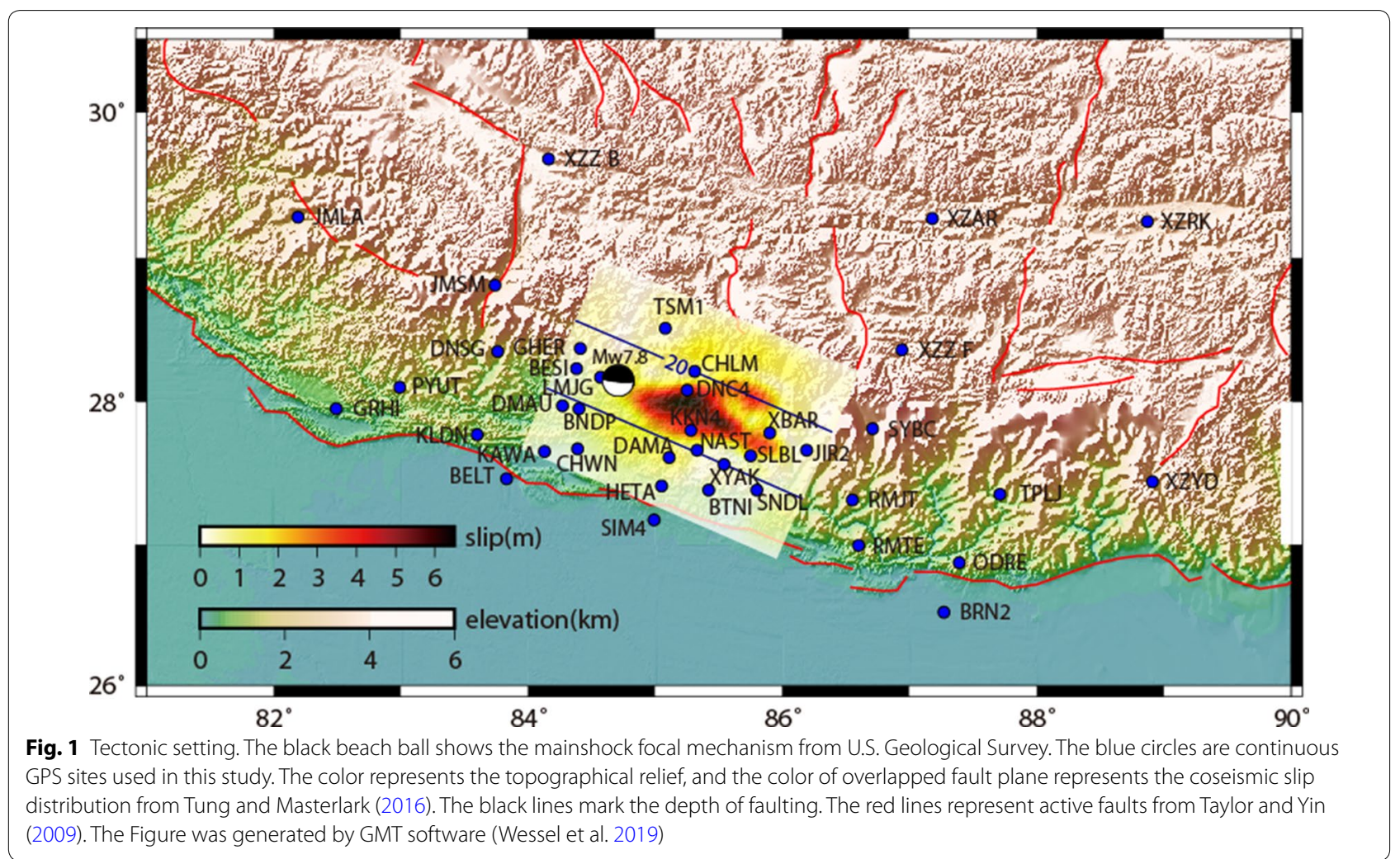


after the earthquake to capture postseismic deformation. The raw RINEX files of these sites are openly available at UNAVCO (ftp://data-out.unavco.org). We additionally collected data from 5 cGPS in South Tibet from the Crustal Movement Observation Network of China (CMONOC) (https://www.cgps.ac.cn/), which began recording in 2011.

We processed the GPS data using the GAMIT/ GLOBK processing software (Herring et al. 2015). Initially, we estimated loosely constrained daily solutions with GAMIT, together with orbits and Earth orientation, tropospheric delay parameters and full covariance matrices. We used data from the 39 cGPS sites from Nepal and South Tibet together with about 80 global distributed core stations of the International GNSS Service (Johnston et al. 2017). Then, we used GLOBK, a smoothing Kalman filter, to transform the loosely constrained solutions to the ITRF2014 reference frame (Altamimi et al. 2016), which is realized by the 80 core stations. The detailed strategy and applied models followed $\mathrm{Su}$ et al. (2019).

We estimated daily displacement time series for the 5 GPS sites in Tibet from 2011 until March 5, 2020, and 34 sites in Nepal from 2011 until January 26, 2019. We compared our time series with solutions from the Nevada Geodetic Laboratory (NGL) (Blewitt et al. 2018) and found the two data sets to be in good agreement (Additional file 1: Fig. S1). Since the GPS coordinate time series for sites in Nepal routinely provided by NGL have longer duration, some of those begin in the 1990s, we used in the time series modeling the NGL solutions for these sites. Considering the possible slight deviation due to the different reference frame realizations of the two solutions, we estimated seven transformation parameters between the NGL and our GAMT/GLOBK solutions to transfer the NGL solutions from IGS 08 (Rebischung et al. 2012) to ITRF2014.

\section{Time series analysis}

The obtained daily time series reflects the surface motion due to the velocities, coseismic displacements, postseismic parameters, seasonal terms (annual and semiannual), and non-tectonic offsets primarily due to any changes in antennas and receivers. The component $(\Delta \mathrm{N}$, $\Delta \mathrm{E}, \Delta \mathrm{U})$ time series at discrete time epochs $t_{i}$ can be modeled independently according to (Nikolaidis 2002):

$$
\begin{aligned}
y\left(t_{i}\right)= & a+b t_{i}+c \sin \left(2 \pi t_{i}\right)+d \cos \left(2 \pi t_{i}\right)+e \sin \left(4 \pi t_{i}\right) \\
& +f \cos \left(4 \pi t_{i}\right)+\sum_{j=1}^{n_{g}} g_{j} H\left(t_{i}-T_{g_{j}}\right) \\
& +\sum_{j=1}^{n_{k}} k_{j} \log \left(1+\frac{t_{i}-T_{k j}}{\tau_{j}}\right) H\left(t_{i}-T_{k j}\right)+\varepsilon_{t_{i}} .
\end{aligned}
$$

The coefficient $a$ is the value at the initial epoch $t_{0}, t_{i}$ denotes the time elapsed (in years) from $t_{0}$, and the linear rate (slope) $b$ represents the interseismic secular tectonic motion in $\mathrm{mm} /$ year. The coefficients $c, d, e$, and $f$ denote annual and semi-annual variations. The seasonal variations in Himalayan range caused by the hydrological loading are up to $30-50 \mathrm{~mm}$ (Fu and Freymueller 2012), and can bias the transient displacements, therefore the periodic terms need to be well dealt with. The magnitudes, $g$, of $n_{g}$ jumps (offsets, steps, and discontinuities) are due to coseismic deformation and/or non-coseismic changes at epochs $T_{g} . H$ denotes the discrete Heaviside function. With respect to the postseismic deformation term, it is often parameterized by exponential or logarithmic model, or combinations of both. The former is often associated with viscoelastic relaxation in the lower crust and the upper mantle (e.g., Shen et al. 1994; Nikolaidis 2002), while the latter is associated with afterslip within the extended rupture area (e.g., Savage and Svarc 1997; Freed et al. 2010). In this paper, we use the logarithmic parametrization, since related research showed that the afterslip mechanism dominated the Gorkha earthquake (Gualandi et al. 2016; Mencin et al. 2016; Sreejith et al. 2016; Zhao et al. 2017; Wang and Fialko 2018; Jiang et al. 2019). The postseismic term includes the amplitudes $k_{j}$, postseismic events starting at epochs $T_{k}$ and a decaying constant $\tau_{j}$, which characterizes how fast the postseismic deformation decays with time. The noise term $\varepsilon_{i}$ is considered as the sum of errors and unmodeled residuals.

Fitting the time series, we can clearly extract the various motions, in particular, the postseismic deformation. For the sake of reliability and obtaining the postseismic parameters with a high signal-to-noise ratio, two more steps were taken: firstly, we estimated secular velocities of sites which operated for more than 2 years before the earthquake, and combined those with GPS velocities provided by Ader et al. (2012) and Bettinelli et al. (2006), through seven parameter transformations to obtain the integrated velocity field in the ITRF2014 reference frame. We then interpolated the velocities using the VISR software (Shen et al. 2015), and re-estimated the time series parameter (Eq. 1), constraining the prior secular velocities. Secondly, motivated by the work of Savage and Svarc (2009) and Barbot et al. (2009), we employed the principal component analysis (PCA) to extract a common postseismic signal for all the displacement time series and their principal components (Additional file 1: Fig. S2). The first principal component clearly represented the postseismic process. On account of the non-linearity of the postseismic deformation model parameter $\tau$, we used trial-and-error over a range of decay values to minimize the sum of the squared residuals between the observations and model. We then fit each coordinate time series 
(Eq. 1) with the optimal $\tau$, and finally extracted the postseismic parameter for each site (Additional file 1: Fig. S3).

\section{Postseismic deformation}

The 4.8-year cumulative postseismic displacements (Fig. 2) associated with the 2015 Gorkha earthquake exhibit similar patterns as the coseismic offsets (Elliott et al. 2016; Gualandi et al. 2016; Mencin et al. 2016). Most GPS sites continue to move southward after the earthquake, showing a dominant thrust feature with minor dextral strike-slip motion along southeast Nepal. As the earthquake ruptured toward the southeast, significant postseismic displacements are primarily distributed across the High Himalaya region. The largest postseismic displacement at site CHLM reaches up to $-93.84 \mathrm{~mm}$, $-31.87 \mathrm{~mm}$ and $36.64 \mathrm{~mm}$ for the $\mathrm{N}, \mathrm{E}, \mathrm{U}$ directions, respectively. Displacements in the north of the rupture area are much larger compared to displacements south of the rupture, which has been confirmed by many studies (Zhao et al. 2017; Wang and Fialko 2018; Jiang et al. 2018; Jiang et al. 2019; Jouanne et al. 2019; Tian et al. 2020), implying the possible existence of afterslip downdip of coseismic rupture. In the vertical direction, most sites experienced ongoing uplift after the Gorkha earthquake, while some sites to the south of the rupture area subsided. The extremely large uplift of site NAST is not reliable, since it suffered from rapid subsidence prior to the mainshock (Zhao et al. 2017). Therefore, we exclude the vertical component of site NAST in modeling the fault slip.

\section{Method of modeling postseismic deformation Finite-element model}

The superiority of finite-element models (FEMs) in simulating the elastic dislocation and the viscoelastic relaxation with heterogeneous material properties has been proven by previous studies (Masterlark et al. 2012;
Hughes et al. 2010; Hines et al. 2016; Hsu et al. 2013; Tung and Masterlark 2016; Pratama et al. 2017). In the view of the strong topographical fluctuations and heterogeneity across the Himalayan region, the spherical FEM with topography and heterogeneity was constructed using the CUBIT software (Blacker et al. 2016).

We defined a spherical shell from the mantle to the surface shaped by the irregular topographical geometry in the target region (Fig. 3) with a resolution of about $1 \mathrm{~km}$ obtained from the SRTM30 software (Becker et al. 2009). The 3D FEM extended over $78-92^{\circ} \mathrm{E}$ and $23-34^{\circ} \mathrm{N}$, from the ground surface to a depth of $300 \mathrm{~km}$, incorporating the upper crust, the middle crust, The lower crust and the upper mantle, and the layer interfaces were interpolated based on CRUST 1.0 (Laske 2013). The heterogeneous elastic material properties were characterized by spatially variable $P$ and $S$ wave velocities, and the density based on CRUST 1.0 (Laske 2013). A spatially variable fully anisotropic viscous model was assigned (Additional file 1: Fig. S4), based on Sun et al. (2013). Furthermore, we assumed zero displacements as side and bottom boundary conditions to take into account their very large extent, along with the stress-free top surface.

The 3D FEM spanned about $1400 \mathrm{~km}, 1200 \mathrm{~km}$ and $300 \mathrm{~km}$ in length, width and depth. The blocks were meshed and discretized by 186,079 tetrahedral elements. The elements in the upper crust were of a length of about $11 \mathrm{~km}$, while the element size increased up to a factor of 5 at the deeper depth in the mantle for the sake of computational time saving; the elements near the fault were dense with a length of about $5 \mathrm{~km}$ to capture strong variable deformation. Because the FEM configuration used by Tung and Masterlark (2016) basically matched ours, we adopted the same refined coseismic rupture to drive viscoelastic relaxation. On the basis of that, we assigned the same fault geometry with a planar patch centered at $\left(27.95^{\circ} \mathrm{N}, 85.27^{\circ} \mathrm{E}\right)$ with a dip and strike of $10^{\circ}$ and
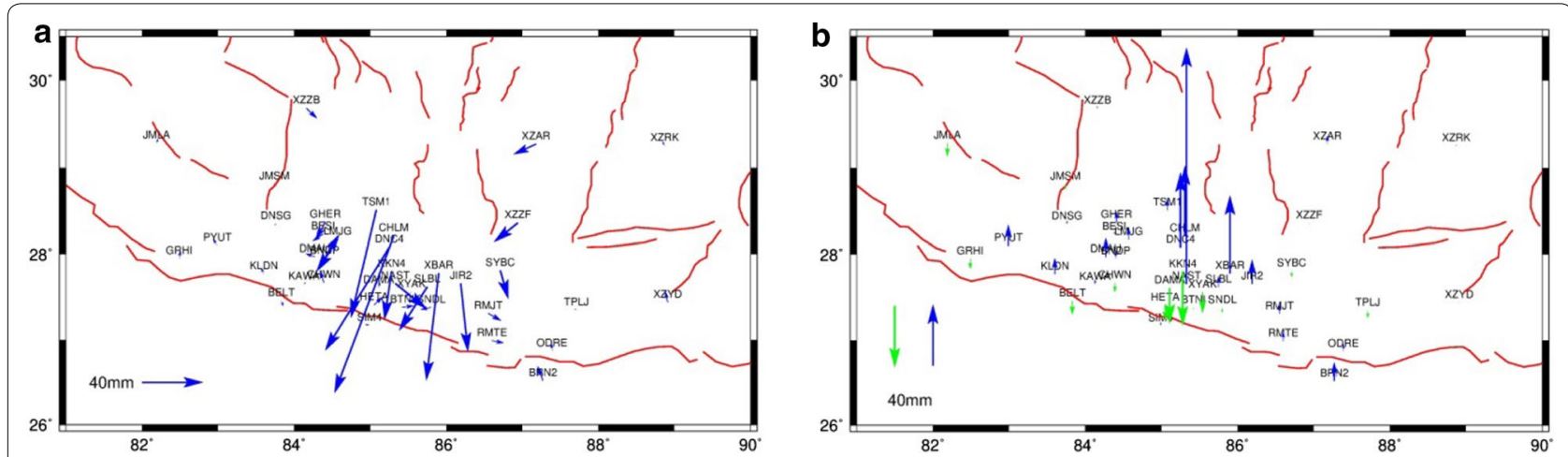

Fig. 2 The cumulative horizontal (a) and vertical (b) postseismic displacements exacted from GPS displacement time series. The red lines represent active faults 

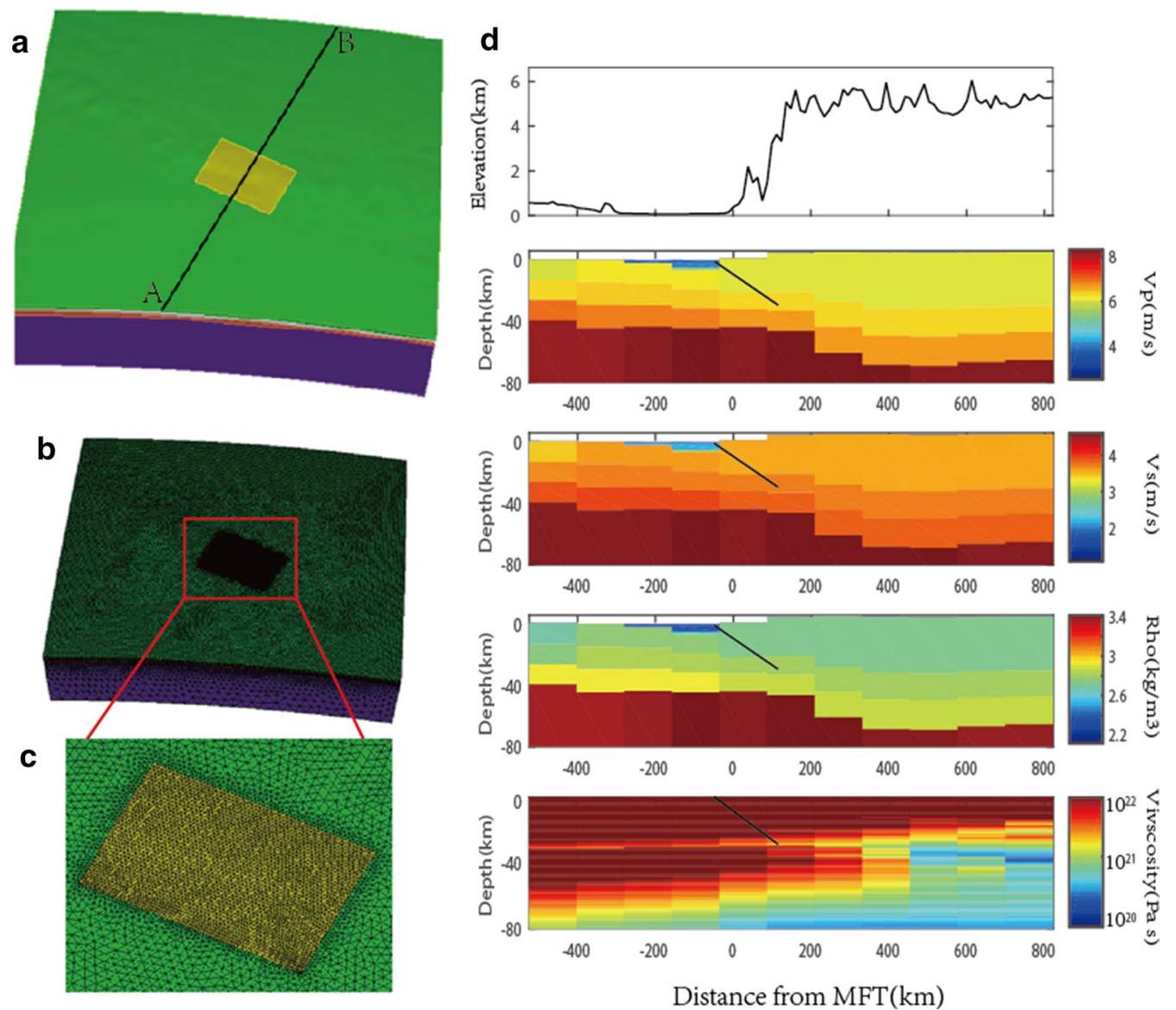

Fig. 3 FEM structure used in the numerical simulation. a The yellow rectangle denotes fault rupture. The top surface exhibits topographical relief. The color blocks denote the upper, middle and lower crust and the mantle, respectively. The profile AB is normal to the MFT. b Map view of the FEM mesh. c The larger view of the FEM mesh in the near-field area of the Gorkha earthquake. $\mathbf{d}$ The elevation, Vp, Vs, density and viscosity variations along the profile AB. The black line is the source rupture plane

$294^{\circ}$ (Tung and Masterlark 2016), and, additionally , extended the fault to the spatial scale of $286 \mathrm{~km} \times 200 \mathrm{~km}$ (length $\times$ width) for the inversion of afterslip.

We performed the calculation with the finite element software PYLITH (Aagaard et al. 2013), which was widely applied to postseismic deformation modeling (Hines et al. 2016; Pratama et al. 2017) and to generate the Green's function (Diao et al. 2014; Hsu et al. 2013; Hines et al. 2016).

\section{Viscoelastic relaxation}

Viscoelastic relaxation due to the coseismic stress changes in the lower crust and upper mantle can explain the postseismic deformation at extensive spatial scales (Freed et al. 2004, 2007; Huang et al. 2014; Rousset et al. 2012). The previous studies calculated the viscoelastic relaxation based on the lateral heterogeneous or layered model, and evaluated viscoelastic relaxation in the postseismic process after the Gorkha earthquake (Zhao et al.
2017; Wang and Fialko 2015; Jiang et al. 2018; Jouanne et al. 2019; Tian et al. 2020; Liu et al. 2020). Differing from these models, we designated spatial variable viscosities to account for the heterogeneous rheological properties across the Himalayan region. Furthermore, we simulated the viscoelastic relaxation with the refined rupture model of Tung and Masterlark (2016), which was inverted by a 3D heterogeneous FEM with input from GPS and INSAR data consistent with other published models (Sreejith et al. 2016; Wang and Fialko 2018),

\section{Afterslip}

The sudden coseismic deformation triggers the aseismic slip on the extended coseismic rupture area (Marone 1991; Perfettini et al. 2004; Hsu et al. 2006; Barbot 2010). The afterslip plays an important role in the postseismic process from several days to several months (Barbot et al. 2008; Segall 2010; Huang et al. 2014). In order to investigate the distribution of afterslip following the Gorkha 
earthquake, we also performed a 3D FEM inversion using the cGPS data as input. The fault, $286 \mathrm{~km}$ long and $200 \mathrm{~km}$ wide, was discretized by a grid of $28 \times 20$ into 560 subfault patches with a dimension of $10.21 \times 10 \mathrm{~km}$, and with Green's functions for each subfault patch due to a unit slip along dip and strike.

With the generated Green's functions, we assumed that the afterslip can be described by a dislocation model of distributed slip. The objective function is:

$$
\mathrm{F}=\|\mathrm{W}(\mathrm{Gm}-\mathrm{d})\|+\beta\left\|\nabla^{2} \mathrm{~m}\right\| .
$$

The first term represents the misfit between modeled and observed displacements, where $\mathrm{W}$ is the weight matrix inferred from observation uncertainties, $G$ is the Green's functions, $m$ is the estimated slip distribution, and $\mathrm{d}$ is the observations. The second term is Laplacian smoothing to avoid abrupt slip variation, where $\beta$ is smoothness and $\nabla^{2}$ is the Laplacian operator.

An algorithm was then developed to invert the smoothed afterslip distribution achieved by a constrained least-squares optimization based on the steepest descent method, motived by Wang et al. (2013). The optimal smoothness was determined by the trade-off between the roughness and data misfit.

\section{Results}

Verification of 3D finite-element model and methodology In order to validate our FEM calculations, we tested a flat layered model with elastic upper and middle crust overlaying a viscoelastic lower crust and mantle, and assigned viscosity values of $1.6 \times 10^{19} \mathrm{~Pa} \cdot \mathrm{s}$ for the lower crust and $10^{20} \mathrm{~Pa} \cdot \mathrm{s}$ for the mantle according to Jiang et al. (2018). Comparing the afterslip and viscoelastic relaxation predicted by our FEM with afterslip by the SDM software (Wang 2013) and viscoelastic relaxation by the PSGRN/ PSCMP software (Wang et al. 2006), respectively (Additional file 1: Figs. S5 and S6), we find coherent patterns and equivalent magnitudes of afterslip and viscoelastic relaxation.

\section{Viscoelastic relaxation}

We characterized the viscoelastic material as the bi-viscoelastic Burgers model, incorporating a transient relaxing Kelvin element in series with a steady-state Maxwell element. For simplicity, we set a constant ratio of 0.1 between Kelvin and Maxwell viscosities (Hu et al. 2016; Hines et al. 2016; Zhao et al. 2017). The viscoelastic relaxation by the forward model exhibits two quadrants of horizontal displacements, namely, pronounced northward motion in the south of the rupture and southward motion in the north. The directions of the predicted viscoelastic relaxation in the south of the rupture area are opposite to the observations. In the vertical direction, there is obvious subsidence in the near field and uplift in the surrounding areas (Fig. 4). The relatively small horizontal and vertical displacements over 4.8 years after Gorkha earthquake imply that viscoelastic relaxation is not indicative of the postseismic process.

We additionally characterized the rheological property as a Maxwell body, and obtained even less significant viscoelastic relaxation (Additional file 1: Fig. S7). Lacking a Kelvin element, Maxwell rheology usually produces smaller viscoelastic relaxation than a Burgers rheology. In the horizontal component, the Maxwell rheology indicates a similar pattern to that of the Burgers rheology. In the vertical direction, there is subsidence in the rupture area for both models, but insignificant uplift to the south of rupture area.

\section{Afterslip}

Next, we modeled the postseismic deformation by afterslip on the fault interface. The knee of the tradeoff curve between the model roughness and data misfit was selected as the optimal smoothing factor (Fig. 5); a smoothing factor of $\beta=0.06$ was chosen in our final solution. With viscoelastic relaxation deducted, the observed horizontal surface displacements are well explained by the downdip afterslip model (Fig. 6). The postseismic displacements due to afterslip are much larger than those associated with viscoelastic relaxation, suggesting that the afterslip plays the dominant role in the postseismic process during the first 4.8 years after the event. The afterslip is mainly distributed downdip of the coseismic rupture, which would be responsible for the much larger postseismic deformation north of the rupture than south of the rupture. The high-slip patch is located at the depth of about $25-30 \mathrm{~km}$ with a peak of $0.28 \mathrm{~m}$. Afterslip occurs at the periphery of the coseismic rupture, in the areas characterized by low aftershock activity (Barbot et al. 2009). The moment release by postseismic afterslip is $7.32 \times 10^{19} \mathrm{~N} \mathrm{~m}$, equivalent to a moment magnitude of $\mathrm{Mw} \sim 7.18$, approximately $6.7 \%$ of the mainshock moment release of $1.09 \times 10^{21} \mathrm{Nm}$ of the coseismic moment release (Tung and Masterlark 2016).

To examine whether the afterslip is well constrained by the GPS data, we conducted a checkerboard test for the resolution (Additional file 1: Fig. S8). The slip model merged $4 \times 4$ subpatches into a single pixel to exhibit $7 \times 5$ checkered asperities (each pixel of $40.85 \times 40 \mathrm{~km}$ ) of 0 and $1.4 \mathrm{~m}$ slip. We then compared the checkerboard pattern slip with the slip model inverted by GPS displacements, and found that slip distribution to be well recovered in spite of minimal distortion and discernible artifacts along the down edge of the slipping patches. The far downdip of the fault was not well 

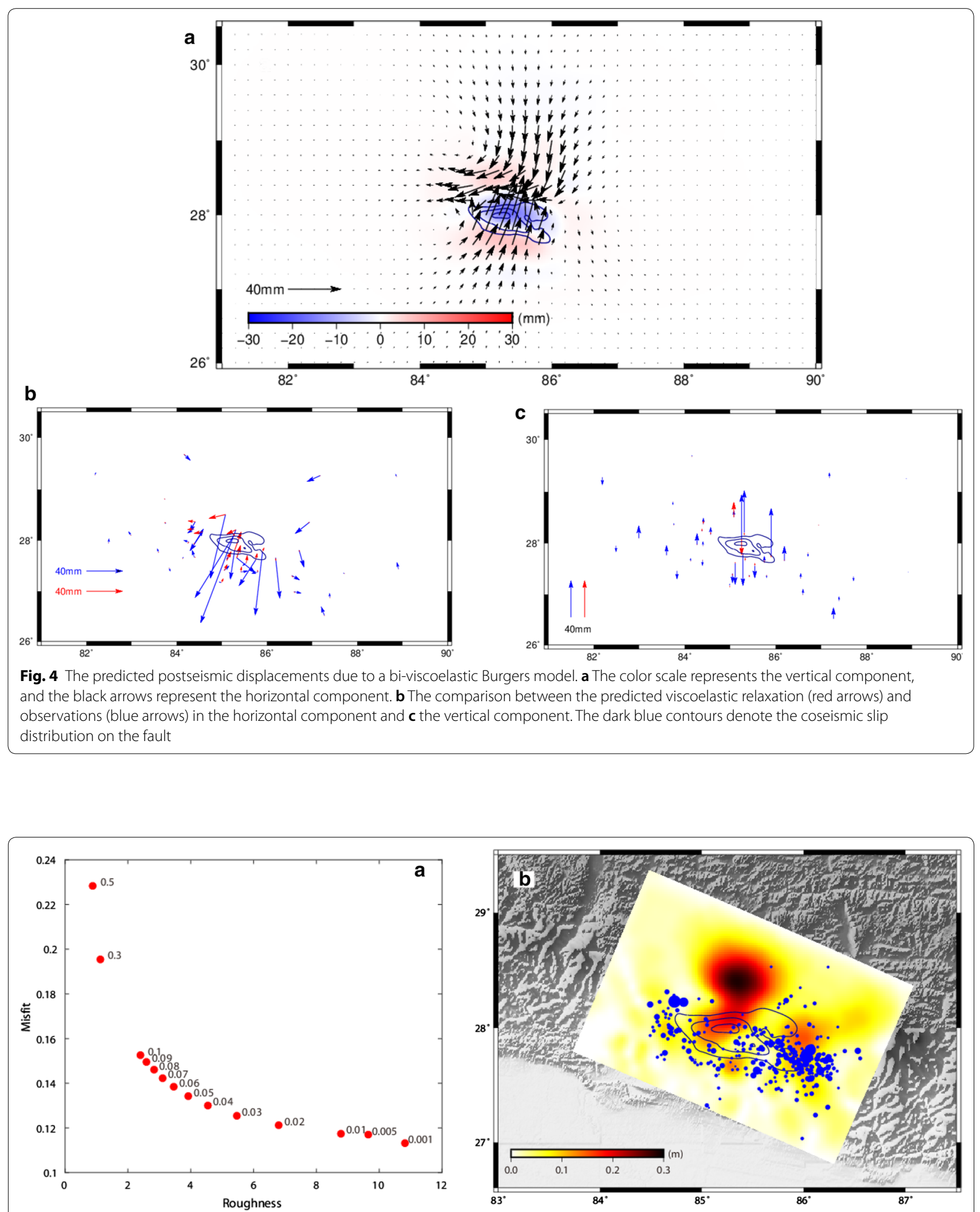

Fig. 5 a Trade-off curve between model roughness and misfit. Numbers indicate the smoothing factor $\beta$. $\mathbf{b}$ The inverted afterslip distribution. The color scale denotes the inverted afterslip distribution. The black contours denote the coseismic slip distribution on the fault. The blue circles denote the aftershocks after the Gorkha earthquake, and the size indicates the magnitude 

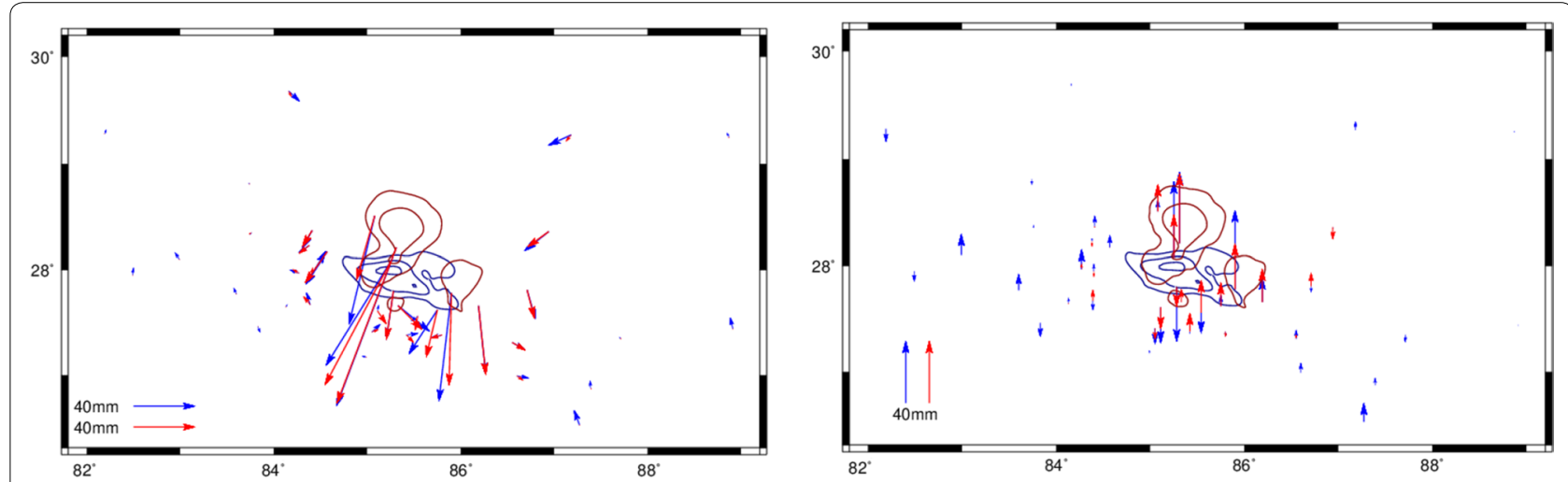

Fig. 6 The observed postseismic displacement (blue arrows) and predicted postseismic displacement (red arrows) due to afterslip. The dark blue and dark red contours denote the coseismic slip and afterslip distribution on the fault

constrained compared to the shallower part of fault, which can be explained by the sparse clustered GPS sites in South Tibet. A joint inversion of GPS and InSAR and/or more GPS sites distribution deployed in South Tibet should provide a better resolution.

\section{Temporal evolution of the deformation and its mechanisms}

We divided the postseismic deformation over 4.8 years after the Gorkha earthquake into four equal time periods of 1.2 years (Fig. 7). The overall patterns of observed postseismic deformation, including both afterslip and postseismic relaxation, during the four time periods are

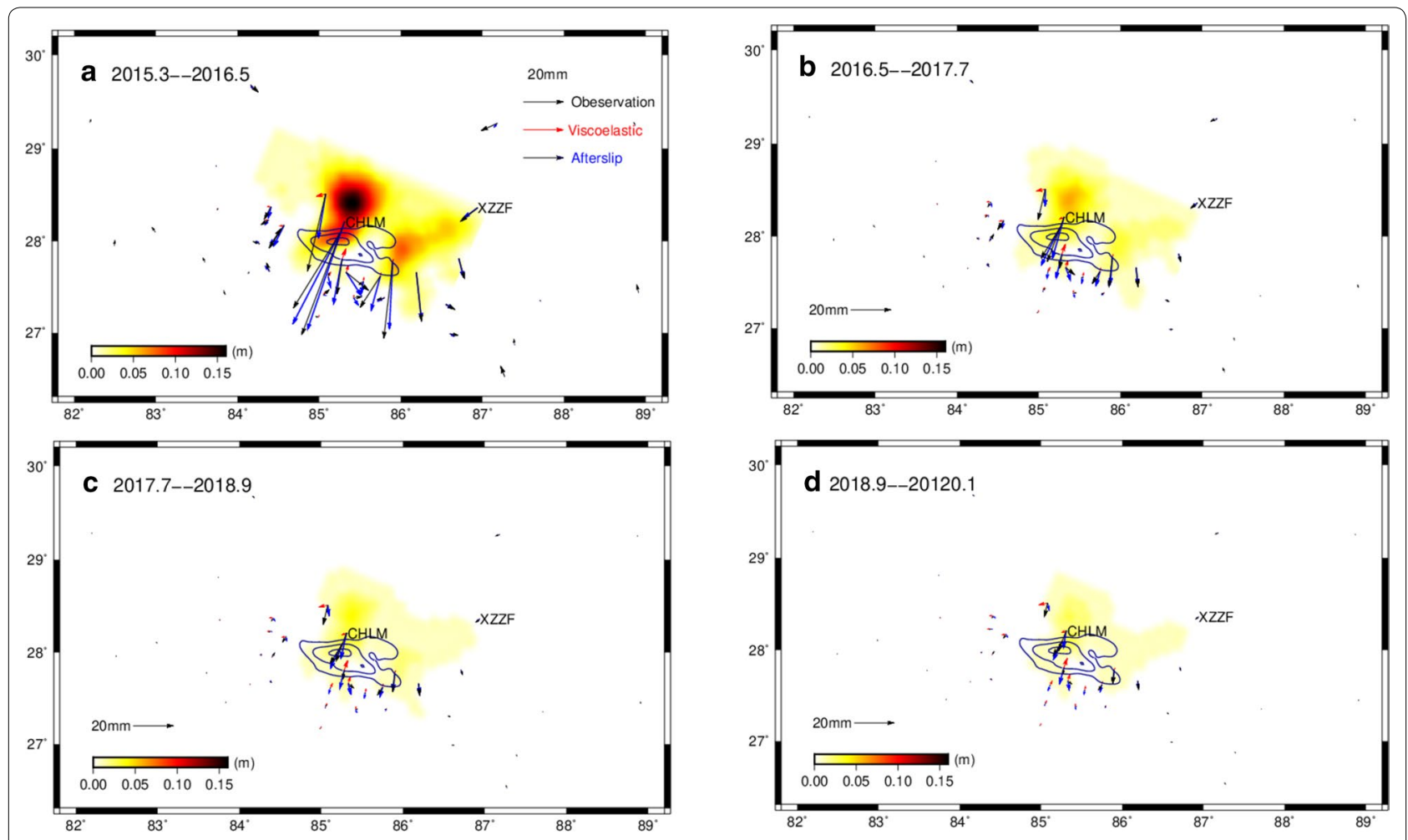

Fig. 7 Comparisons of observed and calculated displacements, including contributions from viscoelastic relaxation and afterslip during the different periods. Horizontal displacements are presented by arrows. The color inset in each panel shows horizontal residuals. The dark blue contours denote the coseismic slip distribution on the fault 
similar: most sites moved southwards, similar to the coseismic displacements. The magnitude of postseismic deformation decays rapidly; the deformation occurring in the first 1.2 years decreases rapidly and averages to about $53.6 \%$ of the entire postseismic signal (maximum slip of $0.16 \mathrm{~m})$, the second interval to about $22.2 \%(0.06 \mathrm{~m})$, the third to about $13.9 \%(0.04 \mathrm{~m})$ and about $10.2 \%(0.03 \mathrm{~m})$ in the last 1.2 years. Snapshots of the spatial distribution due to afterslip alone indicate that most of it occurs downdip of the coseismic rupture. The viscoelastic relaxation component shows a similar pattern, but smaller slip magnitudes. The afterslip downdip of the coseismic rupture is usually associated with velocity-strengthening behavior, results in enduring aseismic slip following the earthquake (Lienkaemper and McFarland 2017; Tian et al. 2020).

Figure 8 shows how the postseismic deformation evolves with time and the individual contributions of afterslip and viscoelastic relaxation. At the site CHLM, the predicted viscoelastic relaxation is opposite to the observation for the $\mathrm{N}$ component. For the E component, the contribution rates of viscoelastic relaxation to postseismic deformation at site CHLM during four different time periods are $19.2 \%, 22.7 \%, 24.8 \%$, and $26.2 \%$, respectively. At the site XZZF in the Tibet, the contribution rates of viscoelastic relaxation to postseismic deformation during four different time periods are $10.5 \%, 12.5 \%$, $13.7 \%$, and $14.5 \%$ for the $\mathrm{N}$ component, and $4.4 \%, 6.0 \%$, $7.1 \%$ and $8.0 \%$ for the $\mathrm{E}$ component. The viscoelastic relaxation plays insignificant role in the postseismic process over the 4.8 years after Gorkha earthquake, but its contribution to the postseismic deformation gradually increases slightly. Longer spans of GPS displacements after the Gorkha earthquake show that postseismic slip is still ongoing.

\section{Discussion}

\section{Effect of heterogeneity under Tibet}

In the context of crustal rheology, evidence from seismic receiver functions, geodetic inversion, resistivity and temperature profiles across the whole Tibetan Plateau show lateral heterogeneous properties (Cattin et al. 2001; Hetényi et al. 2006; Bai et al. 2010; Huang et al. 2014; Avouac et al. 2015; Sun et al.2013). The assumption of lateral uniform viscosity hardly represents the spatially variable viscous properties from the Tibetan plate to the Indian plate, and may inaccurately estimate the extent and magnitude of viscoelastic relaxation in the Himalayan region. Compared with viscoelastic relaxation of our model with that of the flat layered model (Jiang et al. 2018) (Additional file 1: Fig. S5), we find that the softer viscous lower crust over the entire region inevitably brings about an excessive estimation of viscous relaxation in Nepal. The simple heterogeneous rheological models (Zhao et al. 2017; Wang and Fialko 2018; Tian et al. 2020) incorporates the viscous lower crust layer under Tibetan plate. To investigate the difference between a fully heterogeneous model and the simple heterogeneous model, we calculated the viscoelastic relaxation with the software VISCO2.5D (Pollitz 2014), following the simple heterogeneous rheological structure and effective viscosities inferred by Zhao et al. (2017). The viscoelastic relaxation of the simple heterogeneous model exhibits a two-quadrant pattern, northward motion in the south of
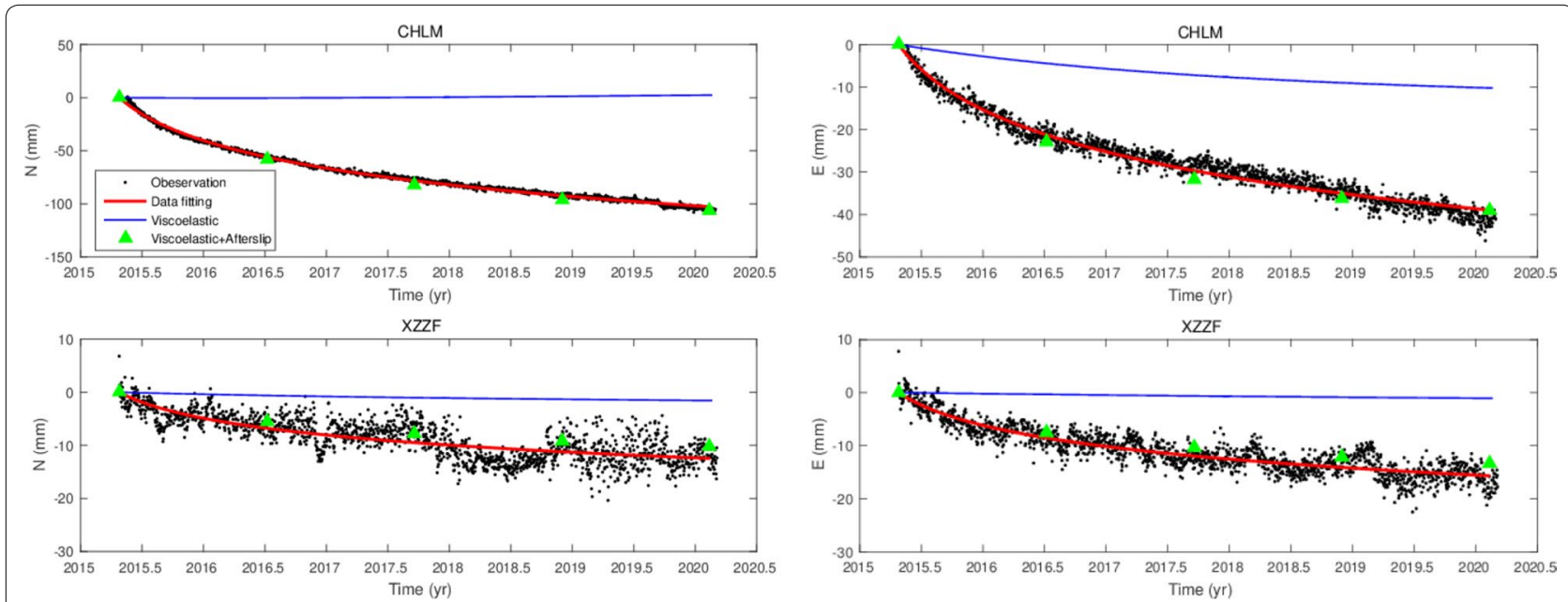

Fig. 8 The postseismic deformation daily displacement time series of the north and east components at GPS sites CHLM and XZZF. Black dots indicate the observed displacements. The red line indicates the data fitting of the postseismic deformation (Eq. 1). The blue line indicates the predicted viscoelastic relaxation. The green triangles indicate the sum of predicted viscoelastic relaxation and the postseismic deformation due to afterslip 
the rupture, southward motion in the north of the rupture, and uplift in the north and subsidence in the south (Additional file 1: Fig. S9). The opposite sign of the predicted displacements with the observations in the south of the rupture area is consistent with our 3D FEM model, consistent with other studies (Wang and Fialko et al. 2018; Jiang et al. 2018). However, it is different from the southward motion predicted by the Tian et al. (2020). Their lower viscosity of the lower crust and mantle under the Tibetan plate with the simple heterogeneous model, results in the larger postseismic displacements in Tibet than our model. Additionally, the distance of the transition zone from the MFT is chosen as $167 \mathrm{~km}$, further than the model of Sun et al. (2013), leading to the smaller magnitude of the postseismic deformation in the south of the rupture area. It is difficult to explain the postseismic deformation, occurring both in Nepal and Tibet, by viscous relaxation.

The lower viscosity of the lower crust and mantle under the Tibetan plateau could account for the postseismic displacements in Tibet, but it leads to a larger discrepancy in the south of the rupture area. The opposite signs between observations and model predictions in the south of the rupture area could be reduced by assuming that a transition from strong to weak lower crust occurs farther to the north (Wang and Fialko 2018). However, this would be inconsistent with the assumption that the topographic slopes are controlled by the viscosity of material in the underlying lower crust (Clark and Royden 2000; Royden et al. 1997).

The postseismic viscoelastic relaxation obtained from geodetic measurements sheds some light on the rheology structure of Himalayan region. Wang and Fialko (2018) and Jiang et al. (2018) inferred $>10^{18} \mathrm{~Pa} \mathrm{~s}$ and $1.6 \times 10^{19} \mathrm{~Pa} \mathrm{~s}$ for the lower crust beneath the Tibet. Zhao et al. (2017) and Tian et al. (2020), respectively, inferred a transient viscosity of $8 \times 10^{18}$ and $5 \times 10^{17} \mathrm{~Pa} \mathrm{~s}$, a steady viscosity of $8 \times 10^{19}$ and $5 \times 10^{18} \mathrm{~Pa} \cdot \mathrm{s}$ for this layer. Liu et al. (2020) deduced that the effective viscosity would decrease northward from $10^{18}$ to $10^{19} \mathrm{~Pa}$ s around the rupture zone to $\sim 3 \times 10^{16}-10^{18} \mathrm{~Pa} \mathrm{~s} \sim 150 \mathrm{~km}$ north. Similar studies were conducted for several earthquakes around Tibetan Plateau. The effective viscosities on the order of magnitude of $10^{18}-10^{19} \mathrm{~Pa}$ s were predicted in studies of the 2001 Mw7.8 Kokoxili earthquake (Ryder et al. 2011; Wen et al. 2012), 2005 Mw7.6 Kashmir earthquake (Wang and Fialko 2014) and 2008 Mw7.9 Wenchuan earthquake (Huang et al. 2014). The above studies, constraining effective viscosities by geodetic postseismic deformation, ignored the dynamic propagating stress changes from viscoelastic relaxation and those induced by any afterslip, and may somewhat estimate lower effective postseismic viscosities (Liu et al. 2020). Strain rates were highest just after the earthquakes, and the effective viscosity were equivalently lower (Liu et al. 2020). The time span is another factor which influences the inferred value of the viscosity. The rheological structure used in this paper, inferred from seismic velocities and GPS velocities, represents the long-term and steady-state viscosity, which is larger than the studies above.

\section{Comparison with the previous afterslip models}

The afterslip associated with the Gorkha earthquake is broadly investigated by several studies based on the GPS and/or InSAR data (Gualandi et al. 2016; Mencin et al. 2016; Sreejith et al. 2016; Zhao et al. 2017; Wang and Fialko 2018; Jiang et al. 2018; Jiang et al. 2019; Tian et al. 2020). These studies have found similar afterslip patterns as our study; afterslip mainly occurs downdip of the rupture area. The high afterslip patch constrained by the joint inversion of GPS and InSAR (Wang and Fialko 2015; Sreejith et al. 2016) data are more easterly than the high afterslip patch constrained by GPS alone, which might be due to the lack of GPS sites in the north of the rupture area. The moment released by afterslip is about $7.32 \times 10^{19} \mathrm{Nm}$ over first 4.8 years, which is echoed by $5.5 \times 10^{19} \mathrm{Nm}$ over first 1 year ( Zhao et al. 2017), $1.2 \times 10^{20} \mathrm{Nm}$ over first 1.6 years (Jiang et al. 2018), $6.0 \times 10^{19} \mathrm{Nm}$ and $1.2 \times 10^{20} \mathrm{Nm}$ over first 2 years (Wang and Fialko 2018; Jiang et al. 2019), and a moment between $1.21 \times 10^{20} \mathrm{Nm}$ and $2.37 \times 10^{20} \mathrm{Nm}$ over 1.16 years (Liu et al. 2020). The low moment release due to afterslip, approximating $6.7 \%$ of the mainshock moment release, is also found for several earthquakes where afterslip occurred downdip of the rupture (Hsu et al. 2006; Ryder et al. 2011; Huang et al. 2014; Lienkaemper and McFarland 2017).

Different from the previous studies, we inverted the afterslip based on the heterogeneous elastic model including the topographic relief and a spherical shell. We compared the afterslip inverted by 3D FEM and flat layered models, and found the WRMS misfit between the afterslip and observations to be $3.18 \mathrm{~mm}$ for the FEM and $3.19 \mathrm{~mm}$ for the flat layered mode. The afterslip distribution of the flat layered model is somewhat smaller from that of the 3D FEM. The high value patch of afterslip inverted by flat layered model is more concentrated and maximum afterslip is up to $0.31 \mathrm{~m}$ (Additional file 1: Fig. S10), larger than the $0.28 \mathrm{~m}$ of the FEM. However, the moment released by afterslip of the flat layered model is equivalent to Mw7.15, lower than Mw7.18 of the 3D FEM.

\section{The potential poroelastic rebound}

When an earthquake occurs, sudden pore fluid pressure changes in the ambient rocks accompany the coseismic 
pressure changes, and then gradually evolve towards an equilibrium condition as the flow of fluid is restored, leading to time-dependent surface deformation (Peltzer et al. 1998; Wang and Kümpel 2003). It is difficult to solve the problem analytically because the deformation and pore pressure fields are coupled through the equilibrium and diffusion equation (Segall 2010). The characteristics of the anisotropic rocks further complicate the calculation. One common way is to calculate postseismic poroelastic rebound through differencing coseismic deformation models under the undrained and drained conditions, represented by variable Poisson's ratios (Fialko 2004; Barbot et al. 2010; Wang and Fialko 2018; Gonzalez-Ortega et al. 2014; Hughes et al. 2010; Hu et al. 2014). We approximately evaluated the potential poroelastic rebound without considering the time-dependent process and any heterogeneity. The poroelastic layer was assumed to be within the top $20 \mathrm{~km}$ of upper crust, while the undrained and drained Poisson's ratios were set to 0.28 and 0.25 , respectively, and the rupture model of Tung and Masterlark (2016) was used to drive the poroelastic rebound. Our results show that the poroelastic rebound (Additional file 1: Fig. S11) spreads out from the rupture area; large poroelastic rebound concentrates the rupture area. However, the maximum displacement is on the order of millimeter, far less than the effects of afterslip and postseismic relaxation, which echoes previous studies (Zhao et al. 2017; Wang and Fialko 2018).

\section{Insight into the seismic risk}

Due to the rapid plate convergence of Indian-Eurasian collision and high strain accumulation, the Himalayan collision zone is prone to frequent devastating earthquakes. During the interseismic period, the MHT is locked from the surface to a distance of approximately $100 \mathrm{~km}$ downdip, corresponding to a depth of 15 to $20 \mathrm{~km}$ based on long time geodetic measurements (Ader et al. 2012; Stevens and Avouac 2015; Liu et al. 2016). The background seismicity along the Himalayan arc is clustered along a relatively narrow zone, which approximately coincides with the downdip end of the locked fault zone (Cattin and Avouac 2000; Bollinger et al. 2004) and the zone of greatest shear stress accumulation (Ader et al.2012). More detailed inversions for distributed interseismic coupling find that the MHT appears nearly fully locked to the south of the front of the Higher Himalaya and fully creeping to the north of it. The transition from unstable to stable slip behavior can be related to the temperature at depth (Ader et al. 2012; Stevens and Avouac 2015).

The Gorkha earthquake ruptured the deep part of the fully locked segment of the MHT (Avouac et al. 2015; Galetzka et al. 2015; Gualandi et al.2016; Elliott et al.
2016; Qiu et al. 2016), only releasing a small amount of seismic moment deficit (Feng et al. 2015; Liu et al. 2015); the inferred afterslip was concentrated at the deeper extent of the coseismic rupture, followed 2 weeks later by the Mw7.3 aftershock, which unzipped the eastern edge of the mainshock (Zhang et al. 2015; Wang and Fialko 2018), leaving the shallow portion and the west of the mainshock rupture areas still locked. Considering the interseismic fault coupling and the small amount of energy released during the coseismic and postseismic periods, the unzipped shallow portion and western segment of the MHT are still at the high seismic risk (Mencin et al. 2016; Elliott et al. 2016; Zhao et al. 2017; Wang and Fialko 2018; Tian et al. 2020; Liu et al. 2020).

\section{Conclusion}

We processed GPS displacement time series of 39 sites in Nepal and South Tibet of China, applying PCA and prior velocity constraints to extract postseismic displacements over 4.8 years after the 2015 Gorkha earthquake. The postseismic displacements show the southward and upward motion around the epicentral area. We then constructed the 3D FEM to explicitly account for the surface topography, earth curvature and heterogeneous material properties to refine the postseismic deformation after the earthquake. With the more realistic FEM, the Burgers rheology generates the viscoelastic relaxation on the order of a centimeter. The viscoelastic relaxation shows the southward motion in the north of the rupture, but nearly exhibits the opposite direction to the observations in the south of the rupture. However, the observed postseismic motions for this earthquake are dominated by afterslip. The inverted afterslip is mainly distributed downdip of the coseismic rupture with a peak of $\sim 28 \mathrm{~cm}$, in the area characterized by low aftershock activities. The moment release by afterslip is $7.32 \times 10^{19} \mathrm{~N} \mathrm{~m}$, equivalent to a moment magnitude $\mathrm{Mw} \sim 7.18$, approximately $6.7 \%$ of the mainshock moment release. Considering the accumulated moment deficit and the small amount energy release during and after the 2015 Gorkha earthquake, the lack of slip on a shallow portion and western segment of the MHT implies continued seismic hazard into the future.

\section{Supplementary information}

Supplementary information accompanies this paper at https://doi. org/10.1186/s40623-020-01296-x.

Additional file 1. Additional figures.

Abbreviations

FEM: Finite-element model; MFT: Main frontal thrust; MHT: Main himalayan thrust; CGPS: Continuous GPS; NGL: Nevada geodetic laboratory; CMONOC: 
Crustal movement observation network of China; PCA: Principal component analysis.

\section{Acknowledgements}

We thank David Mencin for assisting us in the data download. We thank Cecep Pratama, Charles Williams, Trever Hines for helpful instructions on the general Maxwell representations of a Burgers rheology. Comments and suggestions by Liangyu Zhu, Lingyun Ji and two reviewers helped us improve the manuscript. Special thanks to Yehuda Bock for revising the manuscript. We appreciate Rongjiang Wang, Fred F. Pollitz for providing useful software tools: SDM, PSGRN/PSCMP, and VISCO2.5D. The figures were generated using GMT software.

\section{Authors' contributions}

LS and WG designed the research. LS, XS and FS calculated and analyzed the data. LS wrote the software. JY plotted the figures. LS wrote the manuscript with support from WG. All authors read and approved the final manuscript.

\section{Funding}

This work was supported by National Science Foundation of China (41490615), Special Research Project for Earthquake Science of China (2015419024) and the Spark Program of Earthquake Technology of CEA (XH20056Y).

\section{Availability of data and materials}

The datasets used and/or analyzed during the current study are available from the corresponding author on reasonable request. GPS data in Nepal are provided by UNAVCO. Time series of the Nepal station positions are provided by Nevada Geodetic Laboratory. GPS data in South Tibet are from the Crustal Movement Observation Network of China.

\section{Competing interests}

The authors declare that they have no competing interest.

\section{Author details}

1 State Key Laboratory of Earthquake Dynamics, Institute of Geology, China Earthquake Administration, Beijing 100029, China. ${ }^{2}$ Shaanxi Earthquake Agency, Xi'an 710068, China. ${ }^{3}$ Faculty of Geomatics, Lanzhou Jiaotong University, Lanzhou 730070, China.

Received: 2 July 2020 Accepted: 15 October 2020 Published online: 04 November 2020

\section{References}

Aagaard BT, Knepley MG, Williams CA (2013) A domain decomposition approach to implementing fault slip in finite-element models of quasistatic and dynamic crustal deformation. J Geophys Res 118(6):3059-3079

Ader T, Avouac JP, Liu-Zeng J et al (2012) Convergence rate across the Nepal Himalaya and interseismic coupling on the Main Himalayan Thrust: Implications for seismic hazard. J Geophys Res 117(B4):398-399

Altamimi Z, Rebischung P, Métivier L, Collilieux X (2016) ITRF2014: A new release of the International Terrestrial Reference Frame modeling nonlinear station motions. Journal of Geophysical Research: Solid Earth 121(8):6109-6131

Avouac JP, Meng L, Wei S et al (2015) Lower edge of locked Main Himalayan Thrust unzipped by the 2015 Gorkha earthquake. Nat Geosci 8:9

Bai D, Unsworth MJ, Meju MA, Ma X, Teng J, Kong X, Sun Y, Sun J, Wang L, Jiang C, Zhao C, Xiao P, Liu M (2010) Crustal deformation of the eastern Tibetan plateau revealed by magnetotelluric imaging. Nat Geosci 3:358-362

Barbot S, Hamiel Y, Fialko Y (2008) Space geodetic investigation of the coseismic and postseismic deformation due to the 2003 Mw72 Altai earthquake: Implications for the local lithospheric rheology. J. Geophys Res. 113:B03403

Barbot S, Fialko Y, Bock Y (2009) Postseismic deformation due to the Mw6.0, 2004 Parkfield earthquake: Stress-driven creep on a fault with spatially variable rate-and-state friction parameters. J Geophys Res 2009(114):B07405. https://doi.org/10.1029/2008JB005748

Barbot et al (2010) A unified continuum representation of postseismic relaxation mechanisms: semi-analytic models of afterslip, poroelastic rebound and viscoelastic flow. Geophys J Int 182:1124-1140
Bettinelli P, Avouac JP, Flouzat M et al (2006) Plate Motion of India and Interseismic Strain in the Nepal Himalaya from GPS and DORIS Measurements. J Geodesy 80(8-11):567-589

Blacker TD, Owen SJ, Staten ML, Quadros WR, Hanks B, Clark BW, Meyers RJ, Ernst C, Merkley K, Morris R, McBride C. CUBIT Geometry and Mesh Generation Toolkit 15.2 User Documentation. United States: N. p., 2016. Web. doi:https://doi.org/10.2172/1457612

Blewitt G, Hammond WC, Kreemer C (2018) Harnessing the GPS data explosion for interdisciplinary science. Eos 99:1-2

Bilham R, Larson K, Freymueller J (1997) GPS measurements of present-day convergence across the Nepal Himalaya. Nature 386(6620):61-64

Bilham R (2004) Earthquakes in India and the Himalaya: tectonics, geodesy and history. Ann Geophys 47(2-3):839-858

Bollinger L, Avouac JP, Cattin R et al (2004) Stress buildup in the Himalaya. J Geophys Res 109:B11. https://doi.org/10.1029/2003JB002911

Cattin R, Avouac JP (2000) Modeling mountain building and the seismic cycle in the Himalaya of Nepal. J Geophys Res 105(B6):13389

Cattin R, Martelet G, Henry P et al (2001) Gravity anomalies, crustal structure and thermo-mechanical support of the Himalaya of Central Nepal. Geophys J Roy Astron Soc 147(2):381-392

Clark MK, Royden LH (2000) Topographic ooze: building the eastern margin of Tibet by lower crustal flow. Geology 28(8):703-706

Diao F, Xiong X, Wang R et al (2014) Overlapping post-seismic deformation processes: afterslip and viscoelastic relaxation following the $2011 \mathrm{Mw} 9.0$ Tohoku (Japan) earthquake. Geophys J Int 196(1):218-229

Elliott JR, Jolivet R, González PJ, Avouac JP, Hollingsworth J, Searle MP, Stevens VL (2016) Himalayan megathrust geometry and relation to topography revealed by the Gorkha earthquake. Nat Geosci 9(2):174-180

Fialko Y (2004) Evidence of fluid-filled upper crust from observations of post-seismic deformation due to the 1992 Mw7.3 Landers earthquake. J Geophys Res. 109:B08401

Feng G, Li Z, Shan X, Zhang L, Zhang G, Zhu J (2015) Geodetic model of the 2015 pril 25 Mw7.8 Gorkha Nepal Earthquake and Mw7.3 aftershock estimated from InSAR and GPS data. Geophys J Int. 203:896-900

Freed AM, Bürgmann R (2004) Evidence of power-law flow in the Mojave desert mantle. Nature 430(6999):548-551

Freed AM, Bürgmann R, Herring T (2007) Far-reaching transient motions after Mojave earthquakes require broad mantle flow beneath a strong crust. Geophys Res Lett 34(19):228-262

Freed AM, Ali ST, Bürgmann R (2010) Evolution of stress in Southern California for the past 200 years from coseismic, postseismic and interseismic stress changes. Geophys J Roy Astron Soc 169(3):1164-1179

Freed AM, Hashima A, Becker, TW et al (2017) Resolving depth-dependent subduction zone viscosity and afterslip from postseismic displacements following the 2011 Tohoku-oki, Japan earthquake. Earth Planet Sci Lett 2017:279-290

Fu Y, Freymueller JT (2012) Seasonal and long-term vertical deformation in the Nepal Himalaya constrained by GPS and GRACE measurements. J Geophys Res 117:B3. https://doi.org/10.1029/2011JB008925

Galetzka J, Melgar D, Genrich JF et al (2015) Slip pulse and resonance of the Kathmandu basin during the 2015 Gorkha earthquake Nepal. Science 349(6252):1091-1095

Gonzalez-Ortega A, Fialko Y, Sandwell D et al (2014) El Mayor-Cucapah (Mw 7.2) earthquake: Early near-field postseismic deformation from InSAR and GPS observations. J Geophys Res Solid Earth 119(2):1482-1497

Gualandi A, Avouac J-P, Galetzka J, Genrich JF, Blewitt G, Adhikari LB, Liu-Zeng $J$ (2016) Pre- and post-seismic deformation related to the 2015, Mw 7.8 Gorkha earthquake Nepal. Tectonophysics 714-715:90-106

Hetényi G, Cattin R, Vergne J, Nábělek JL (2006) The effective elastic thickness of the India Plate from receiver function imaging, gravity anomalies and thermomechanical modelling. Geophys J Int 167:1106-1118

Hines TT, Hetland EA (2016) Rapid and simultaneous estimation of fault slip and heterogeneous lithospheric viscosity from post-seismic deformation. Geophys J Int 204:569-582

Hsu YJ, Simons M, Avouac JP et al (2006) Frictional Afterslip Following the 2005 Nias-Simeulue Earthquake, Sumatra. Science 312(5782):1921

Hsu Y, Simons M, Williams C et al (2013) Three-dimensional FEM derived elastic Green's functions for the coseismic deformation of the 2005 Mw8.7 NiasSimeulue, Sumatra earthquake. Geochem Geophys Geosyst 12:7 
Hu Y, Jeffrey T et al (2014) Contributions of poroelastic rebound and a weak volcanic arc to the postseismic deformation of the 2011 Tohoku earthquake. Earth Planets Space 66(1):106

Hu Y, Bürgmann R, Banerjee P et al (2016) Asthenosphere rheology inferred from observations of the 2012 Indian Ocean earthquake. Nature. https:// doi.org/10.1038/nature19787

Huang M-H, Bürgmann R, Freed AM (2014) Probing the lithospheric rheology across the eastern margin of the Tibetan Plateau. Earth Planet Sci Lett 396:88-96

Hughes KLH, Masterlark T, Mooney WD (2010) Poroelastic stress-triggering of the 2005 M8.7 Nias earthquake by the 2004 M92 Sumatra-Andaman earthquake. Earth Planet Sci Lett 293(3-4):289-299. https://doi. org/10.1016/j.epsl.2010.02.043

Johnston G, Riddell A, Hausler GT, international GNSS service. (2017) In Springer handbook of global navigation satellite systems. Springer, Cham, pp 967-982

Jouanne F, Gajurel A, Mugnier JL et al (2019) Postseismic deformation following the April 25, 2015 Gorkha earthquake (Nepal): Afterslip versus viscous relaxation. J Asian Earth Sci 176:105-119

Jiang G, Wang Y, Wen Y et al (2019) Afterslip evolution on the crustal ramp of the Main Himalayan Thrust fault following the 2015 Mw 78 Gorkha (Nepal) earthquake. Tectonophysics 758:29-43

Jiang Z, Yuan L, Huang D, Yang Z, Hassan A (2018) Postseismic deformation associated with the 2015 mw 7.8 Gorkha earthquake, Nepal: investigating ongoing afterslip and constraining crustal rheology. J Asian Earth Sci. https://doi.org/10.1016/j.jseaes.2017.12.039

Klein E, Fleitout L, Vigny C et al (2016) Afterslip and viscoelastic relaxation model inferred from the large-scale post-seismic deformation following the 2010 Mw 88 Maule earthquake (Chile). Geophys J Int 205(3):1455-1472

Kyriakopoulos C, Masterlark T, Stramondo S, Chini M, Bignami C (2013) Coseismic slip distribution for the Mw 92011 Tohoku-Oki earthquake derived from 3-D FE modeling. J Geophys Res Solid Earth 118:3837-3847

Kumar S, Wesnousky SG, Rockwell TK et al (2001) Earthquake recurrence and rupture dynamics of Himalayan Frontal Thrust, India. Science 294(5550):2328-2331

Laske, G., Masters, G., Ma, Z. and Pasyanos, M. E. CRUST1.0: an updated global model of Earth's crust. Geophys. Res. Abstr. 15, Abstract EGU2013-2658 (2013).

Lavé J, Avouac J-P (2000) Active folding of fluvial terraces across the Siwaliks Hills, Himalayas of Central Nepal. J Geophys Res 105(B3):5735-5770. https ://doi.org/10.1029/1999JB900292

Lindsey EO, Natsuaki R, Xu X, Shimada M, Hashimoto M, Melgar D, Sandwell DT (2015) Line-of-sight displacement from ALOS-2 interferometry: Mw 7.8 Gorkha earthquake and Mw 7.3 aftershock. Geophys Res Lett 42:66556661. https://doi.org/10.1002/2015GL065385

Lienkaemper JJ, McFarland FS (2017) Long-term afterslip of the 2004 M 6.0 Parkfield, California, earthquake - implications for forecasting amount and duration of afterslip on other major creeping faults. Bull Seismol Soc Am 107:1082-1093

Liu C, Zheng Y, Wang R, Shan B, Xie Z, Xiong X, Ge C (2016) Rupture processes of the 2015 Mw 7.9 Gorkha earthquake and its Mw 7.3 aftershock and their implications on the seismic risk. Tectonophysics 682:264-277

Liu J, Ji C, Zhang J et al (2015) Tectonic setting and general features of coseismic rupture of the 25 April, 2015 Mw 7.8 Gorkha, Nepal earthquake (in Chinese). Chin Sci Bull 60(26):40-2655. https://doi.org/10.1360/N9720 $15-00559$

Liu J, Zhang Z, Rollins C, et al (2020) Postseismic deformation following the 2015 Mw7.8 Gorkha (Nepal) earthquake: new GPS data, kinematic and dynamic models, and the roles of afterslip and viscoelastic relaxation. J Geophys Res

Marone CJ, Scholz CH, Bilham R (1991) On the mechanics of earthquake afterslip. J Geophys Res 96:8441-8452

Masterlark T, DeMets C, Wang H, Sanchez O, Stock J (2001) Homogeneous vs heterogeneous subduction zone models: Coseismic and postseismic deformation. Geophys Res Lett 28(21):4047-4050. https://doi. org/10.1029/2001GL013612

Masterlark T (2003) Finite element model predictions of static deformation from dislocation sources in a subduction zone: Sensitivities to homogeneous, isotropic, Poisson-solid, and half-space assumptions. J Geophys Res 108(B1 1):2540. https://doi.org/10.1029/2002JB002296
Masterlark T, Feigl KL, Haney M, Stone J, Thurber C, Ronchin E (2012) Nonlinear estimation of geometric parameters in FEMs of volcano deformation: Integrating tomography models and geodetic data for Okmok volcano, Alaska. J Geophys Res 117:B02407. https://doi.org/10.1029/2011JB008811

Mencin D, Bendick R, Upreti BN, Adhikari DP, Gajurel AP, Bhattarai RR, Bilham R (2016) Himalayan strain reservoir inferred from limited afterslip following the Gorkha earthquake. Nat Geosci 9:533-537. https://doi.org/10.1038/ ngeo27344

Monsalve G, Sheehan A, Schulte-Pelkum V, Rajaure S, Pandey M, Wu F (2006) Seismicity and one-dimensional velocity structure of the Himalayan collision zone: earthquakes in the crust and upper mantle. J Geophys Res 111:B10301. https://doi.org/10.1029/2005JB004062

Nikolaidis RM (2002) Observation of geodetic and seismic deformation with the global positioning system[D]. Univ. of Calif, San Diego

Paul S (2010) Earthquake and volcano deformation. Princeton University Press, Princeton

Peltzer G, Rosen P, Rogez F et al (1998) Poroelastic rebound along the Landers 1992 earthquake surface rupture. J Geophys Res Atmosp 1033(B12):30131-30146

Perfettini H, Avouac J (2004) Postseismic relaxation driven by brittle creep: A possible mechanism to reconcile geodetic measurements and the decay rate of aftershocks, application to the Chi-Chi earthquake, Taiwan. J Geophys Res Solid Earth. 109:B2

Pollitz F, Vergnolle M, Calais E (2003) Fault Interaction and Stress Triggering of 20th Century Earthquakes in Mongolia. J Geophys Res Solid Earth 108:B10

Pollitz FF (2014) Post-earthquake relaxation using a spectral element method: 2.5- D case. Geophys J Int 198:308-326

Pratama C, Ito T, Sasajima R, Tabei T et al (2017) Transient rheology of the oceanic asthenosphere following the 2012 indian ocean earthquake inferred from geodetic data. J Asian Earth Sci 147:1

Qiu Q, Hill EM, Barbot S, Hubbard J, Feng W, Lindsey EO, Tapponnier P (2016) The mechanism of partial rupture of a locked megathrust: The role of fault morphology. Geology 44(10):875-878. https://doi.org/10.1130/ G38178.1

Rebischung P, Griffiths J, Ray J, Schmid R, Collilieux X, Garayt B (2012) IGS08: the IGS realization of ITRF2008. GPS Solutions 16(4):483-494

Rousset B, Barbot S, Avouac J-P, Hsu Y-J (2012) Postseismic deformation following the 1999 Chi-Chi earthquake, Taiwan: Implication for lower-crust rheology. J Geophys Res 117:B12405. https://doi.org/10.1029/2012JB0095 71

Royden LH, Burchfiel BC, King RW et al (1997) Surface deformation and lower crustal flow in eastern Tibet. Science 276:788-790

Ryder I, Bürgmann R, Pollitz F (2011) Lower crustal relaxation beneath the Tibetan Plateau and Qaidam Basin following the 2001 Kokoxili earthquake. Geophys J Int 187:613-630

Sapkota SN, Bollinger L, Klinger $Y$ et al (2013) Primary surface ruptures of the great Himalayan earthquakes in 1934 and 1255. Nat Geosci 6(2):152-152

Savage J, Svarc J (2009) Postseismic relaxation following the 1992 M7.3 Landers and 1999 M7.1 Hector Mine earthquakes, southern California. J Geophys Res. 114:B01401. https://doi.org/10.1029/2008JB005938

Schulte-Pelkum V, Monsalve G, Sheehan A, Pandey MR, Sapkota S, Bilham R, Wu F (2005) Imaging the Indian subcontinent beneath the Himalaya. Nature 435(7046):1222-1225. https://doi.org/10.1038/nature03678

Shen Z, Jackson DD, Feng Y, Cline MW, Kim M, Fang P, Bock Y (1994) Postseismic Deformation Following the Landers Earthquake, California, 28 June 1992. Bull Seismol Soc Am 84(3):780-791

Shen Z-K, Wang M, Zeng Y, Wang F (2015) Strain determination using spatially discrete geodetic data. Bull Seismol Soc Am 105(4):2117-2127. https:// doi.org/10.1785/0120140247

Sreejith K, Sunil P, Agrawal R, Saji AP, Ramesh D, Rajawat A (2016) Coseismic and early postseismic deformation due to the 25 April 2015, Mw7.8 Gorkha, Nepal, earthquake from InSAR and GPS measurements. Geophys Res Lett 43(7):3160-3168

Stevens VL, Avouac J-P (2015) Interseismic coupling on the Main Himalayan thrust. Geophys Res Lett 42:5828-5837. https://doi.org/10.1002/2015G L064845

Su X, Yao L, Wu W, Meng G, Su L, Xiong R, Hong S (2019) Crustal Deformation on the Northeastern margin of the Tibetan Plateau from continuous GPS observations. Remote Sens 11:34 
Suito H (2017) Importance of rheological heterogeneity for interpreting viscoelastic relaxation caused by the 2011 Tohoku-Oki earthquake. Earth Planets Space 69:1

Sun Y, Dong S, Zhang H et al (2013) 3D thermal structure of the continental lithosphere beneath China and adjacent regionss. J Asian Earth Sci 62:697-704

Taylor M, Yin A (2009) Active structures of the Himalayan-Tibetan orogen and their relationships to earthquake distribution, contemporary strain field, andCenozoic volcanism. Geosphere 5(3):199-214

Tian Z, Freymueller JT, Yang Z (2020) Spatio-temporal variations of afterslip and viscoelastic relaxation following the Mw7.8 Gorkha (Nepal) earthquake. Earth Planet Sci Lett. https://doi.org/10.1016/j.epsl.2019.116031

Tung S, MasterlarkT (2016) Coseismic slip distribution of the 2015 Mw7.8 Gorkha, Nepal, earthquake from joint inversion of GPS and InSAR data for slip within a 3-D heterogeneous Domain. J Geophys Res Solid Earth 121:3479-3503. https://doi.org/10.1002/2015JB012497

U.S. Geological Survey (USGS) (2015), USGS National Earthquake Information Center

Wang K, Fialko Y (2014) Space geodetic observations and models of postseismic deformation due to the 2005 M76 Kashmir (Pakistan) earthquake. J Geophys Res Solid Earth 119:7306-7318

Wang K, Fialko Y (2015) Slip model of the 2015 Mw7.8 Gorkha (Nepal) earthquake from inversions of ALOS-2 and GPS data. Geophys Res Lett 42:7452-7458

Wang K, Fialko Y (2018) Observations and modeling of coseismic and postseismic deformation due to the 2015 Mw 7.8 Gorkha (Nepal) earthquake. J Geophys Res 1:123. https://doi.org/10.1002/2017JB014620

Wang R. SDM - A geodetic inversion code incorporating with layered crust structure and curved fault geometry[C]// Egu General Assembly Conference. 2013.
Wang R, Kümpel H-J (2003) Poroelasticity: Efficient modeling of strongly coupled, slow deformation processes in a multilayered half-space. Geophysics 68(2):705-717

Wang R, Lorenzo-Martín F, Roth F (2006) PSGRN/PSCMP_A new code for calculating co- and post-seismic deformation, geoid and gravity changes based on the viscoelastic-gravitational dislocation theory. Comput Geosci 32(4):527-541. https://doi.org/10.1016/j.cageo.2005.08.006

Wen Y, Li Z, Xu C, Ryder I, Bürgmann R (2012) Postseismic motion after the 2001 Mw 7.8 Kokoxili earthquake in Tibet observed by InSAR time series. J Geophys Res Solid Earth 117:B8

Wiseman K, Burgmann R, Freed AM et al (2015) Viscoelastic relaxation in a heterogeneous Earth following the 2004 Sumatra-Andaman earthquake. Earth Planet Sci Lett 2015:308-317

Wessel P, Luis JF, Uieda L, Scharroo R, Wobbe F, Smith WHF, Tian D (2019) The generic mapping tools version 6. Geochem Geophys Geosyst 20:5556-5564

Zhao B, Bürgmann R, Wang D, Tan K, Du R, Zhang R (2017) Dominant controls of downdip afterslip and viscous relaxation on the postseismic displacements following the Mw7.9 Gorkha. Nepal, earthquake 122:8376-8401. https://doi.org/10.1002/2017JB014366

Zhang G, Hetland E, Shan X (2015) Slip in the 2015 Mw 7.9 Gorkha and Mw 7.3 Kodari, Nepal, Earthquakes Revealed by Seismic and Geodetic Data: Delayed Slip in the Gorkha and Slip Deficit between the Two Earthquakes. Seismol Res Lett 86(6):1578-1586. https://doi.org/10.1785/02201 50139

\section{Publisher's Note}

Springer Nature remains neutral with regard to jurisdictional claims in published maps and institutional affiliations.

\section{Submit your manuscript to a SpringerOpen ${ }^{\circ}$ journal and benefit from:}

- Convenient online submission

- Rigorous peer review

- Open access: articles freely available online

- High visibility within the field

- Retaining the copyright to your article

Submit your next manuscript at $\boldsymbol{\nabla}$ springeropen.com 